\title{
O eco de uma interpretação
}

Interpretação e Superinterpretação, de Umberto Eco ${ }^{1}$

Denise Dantas

Universidade Federal do Rio Grande do Norte

Objetivo significa sempre 'humanamente objetivo', o que pode corresponder exatamente a 'historicamente subjetivo', isto é, objetivo significaria 'universal subjetivo'.

Gramsci

$\mathrm{E}$

m primeiro lugar, quero concordar com Stephan Collini quando diz, na sua Introdução a Interpretação e Superinterpretação (Eco, 1993), em foco na presente análise, que as Conferências Tanner mantiveram-se fiéis à sua finalidade de constituição de um fórum de debate sobre valores humanos debaixo do prisma da ciência, quando, em 1990, abrigaram Umberto Eco como seu conferencista. Pois esta obra, que reúne as apresentações ali havidas, propicia ao leitor uma viagem ao longo de questões centrais nas ciências humanas, como é o caso da tensão objetividade-subjetividade, trazida à discussão por Eco, a carregarem por trás de si a questão mais nuclear da concepção de homem daqueles que fazem ciência. Estabelece-se, então, em Clare Hall, Cambridge, o cenário onde Eco debate suas idéias com outros estudiosos que têm divergências em relação às suas posições: Richard Rorty, Jonathan Culler e Christine Brooke-Rose. 
$\mathrm{Na}$ sua primeira apresentação, rebatendo o que fora, a seu ver, uma apreensão parcializada do que ele defendia na sua Obra Aberta, algo de muito importante é posto em cena para a análise da relação dialética entre os direitos dos textos e os direitos do leitor: a potencialidade ou virtualidade como uma dimensão constituinte de uma gama de possibilidades - tão amplas quanto são as infinitas variantes singulares do ser humano que, ao se realizarem como fenômeno concreto, sofrem uma limitação determinada pela conjugação dos fatores intentio operis e intentio lectoris que se realizam, entrando em cena no momento em que se inicia a atividade interpretativa. A "semiótica potencialmente ilimitada" não comporta como corolário que uma mensagem possa significar qualquer coisa. Embora não de forma mecanicista, há uma determinação, pois a interpretação de uma obra é algo histórico ${ }^{2}$. Esta é a primeira defesa de Eco, que segue falando da persistência de elementos herméticos no irracionalismo ocidental moderno na qual, em situação de extrema influência, é possível encontrar a crença e a valorização do misterioso como aquilo que existe de mais profundo a ser conhecido, pela simples condição de ser obscuro.

Se bem que não considere a intentio auctoris pré-textual como a fonte do significado, Eco não deixa de reconhecer que ali se encontra uma origem genética ${ }^{3}$ do que está sendo interpretado. Não seria possível desconhecer, acredito, que a intencionalidade é cunhada pelo caráter consciente da ação humana e que a dimensão inconsciente, sempre definitivamente presente na sua configuração, permanece inacessível ao seu próprio autor, mas, se o oculta, também o revela, o que acontece em todos os momentos do nosso estar-no-mundo. Contudo, Eco deslinda a necessidade de ultrapassagem do autor empírico - com sua intencionalidade originária - para uma intentio operis como forma de alcance do objetivo do texto, que não se encontra na relação de um leitor empírico com a obra, mas na abstrata tipologia de um leitor-modelo que, gozando de autonomia relativa, seja capaz de respeitar os limites da liberdade possível sem se fixar numa ignorância da alteridade que existe nessa Eu-Tu com a obra.

Ao analisar as possibilidades e limites da interpretação, Eco deixa bem claro que é imprescindível a consideração do outro, que há um 
sistema dialógico em jogo, o que, inevitavelmente, funciona como uma barreira à idéia de dissociação entre as dimensões objetiva e subjetiva de uma obra e uma ação humana. Porque este outro, por sua vez, irá compor um sistema triádico com um outro outro, entrando no tecido da significação social, na medida em que o coletivo formado por um par não poderia sustentar o movimento de construção histórica ad infinitum.

Este é um dos pontos de aparente desencontro, ao meu ver ${ }^{4}$, entre Eco e Rorty. Digo aparente porque considero que Rorty contrapõe a Eco algumas considerações que estariam melhor situadas em outro nível de análise. Quando ele discorda da diferença que Eco utiliza com relação ao significado de usar ou interpretar um texto, o que me parece é que - fazendo uma analogia com o que Gramsci quer dizer com "Todos os homens são filósofos" (Gramsci, 1987, p. 11) Rorty estaria a referir-se à interpretação apenas em um dos seus níveis de ocorrência mais simples, enquanto Eco, ao distinguir os dois termos, estaria enquadrando a questão das alteridades que constituem a pluralidade do mundo humano. E aí, a legitimidade, o reconhecimento público são necessários parâmetros de avaliação do que se constitui socialmente para além da subjetividade individual, pura e simplesmente, produção que desaparece no espaço de vida do seu criador singular. O termo "darwinismo cultural" utilizado por Eco traduz bem o sentido de continuidade, de permanência como um dos pólos da passagem histórica de um momento passado para um momento presente, a conjugar-se, dialeticamente, com a descontinuidade e a mudança.

Se Rorty bateu forte nesta tecla da distinção feita por Eco entre uso e interpretação, não foi aí que Culler interpretou que ele estava divergindo mais, e sim, no tocante ao proposto abandono, na atividade interpretativa, de um sistema em que princípios e mecanismos estruturais servissem de guias para a busca de decifração de códigos. Em uma posição própria, Culler também se opõe a Eco, entendendo que o mesmo toma por superinterpretação aquilo que inclui a possibilidade do novo, o momento da apreensão da alteridade imbuído da capacidade criativa de problematização, ou seja, a 
supracomprensão ${ }^{6}$, enfatizando o seu caráter relacional. O significado emergente no contexto dispensaria um sistema anterior, de que o hermeneuta se valeria para desempenhar seu papel. Culler, partidário da desconstrução, defende que o texto não impõe limites ao profícuo "assombro" que, pela riqueza de suas consequiências, deveria ser incentivado na atividade hermenêutica.

$\mathrm{Na}$ sua réplica aos debatedores, Eco sintetiza seu posicionamento e clarifica os seus pontos de aproximação e distanciamento dos demais membros da mesa. Fundamentalmente, postula que há graus de aceitabilidade de interpretações e que isto resulta do devido respeito pelo dialética da intentio operis com a intentio lectoris. O que parece ficar cristalinamente esclarecido é que ele não se insurge contra a criatividade do intérprete. Entretanto, advoga que os limites para que isto não gere uma ruptura (o que seria o momento da produção de uma obra, não mais caracterizada como interpretação de um texto) encontram-se na dinâmica que resulta da interação entre uma "fala", uma "escuta" e uma "fala", sem perda dos elos que permitem o encontro histórico.

Eco reinsere a questão básica da relação singularidade-pluralidade da vivência humana, a dimensão pública como indispensável à exploração do mundo das idéias, por ser, ela mesma, uma dimensão do humano.

\section{Referências}

Eco, U. (1993). Interpretação e Superinterpretação. São Paulo: Martins Fontes. Gramsci, A. (1987). Concepção dialética da história ( $7^{\mathrm{a}}$. ed.). Rio de Janeiro: Civilização Brasileira.

Palmer, R. E. (1969). Hermenêutica. Lisboa: Edições 70. 


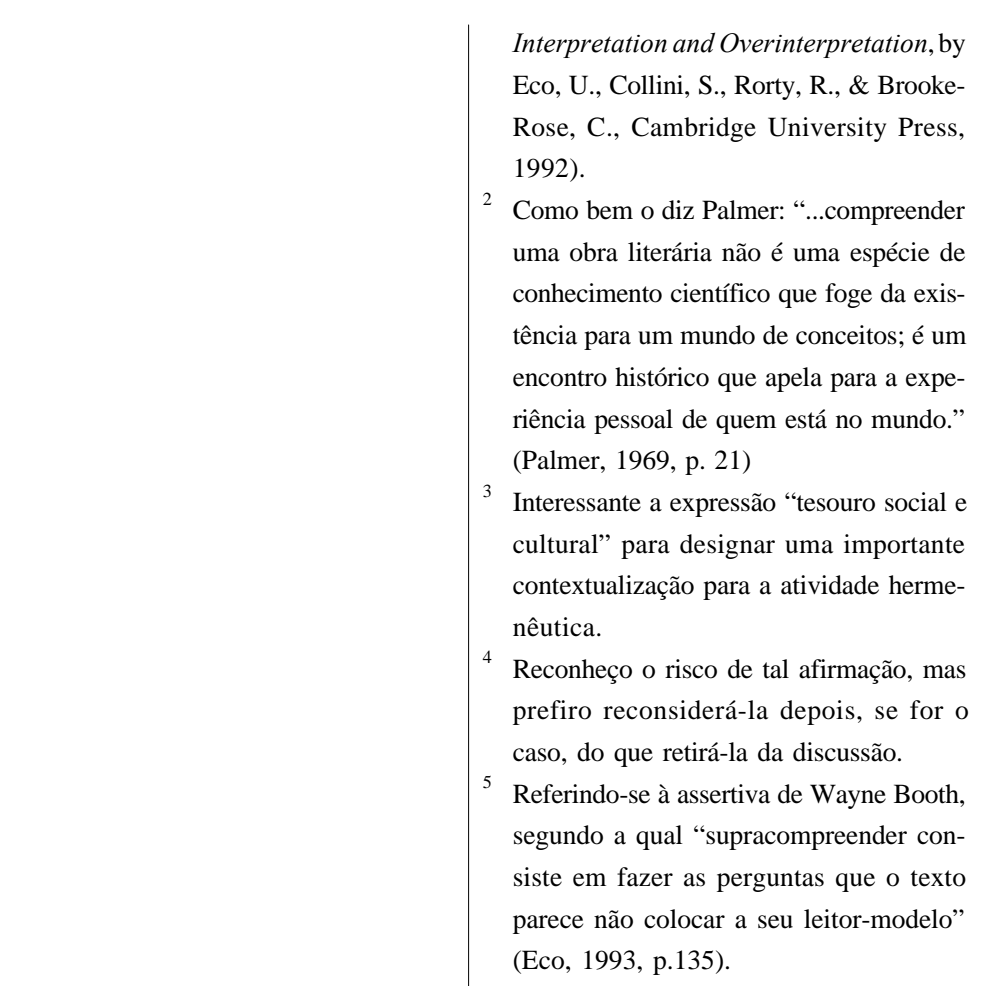

Denise Ramalho Dantas de Araújo é psicóloga, Professora Assistente do Departamento de Psicologia da Universidade Federal do Rio Grande do Norte (UFRN). Mestre em Ciências Sociais pela UFRN, doutoranda em Psicologia Clínica pela Universidade de São Paulo. Endereço para correspondência: Rua dos Tororós, 857/501, 59.054-550, Natal, RN.

E-mail: gerundio@digi.com.br e gerundio@cchla.ufrn.br.

Interpretation and Overinterpretation, by Eco, U., Collini, S., Rorty, R., \& BrookeRose, C., Cambridge University Press, 1992)

Como bem o diz Palmer: “...compreender uma obra literária não é uma espécie de conhecimento científico que foge da existência para um mundo de conceitos; é um encontro histórico que apela para a experiência pessoal de quem está no mundo." (Palmer, 1969, p. 21)

Interessante a expressão "tesouro social e cultural" para designar uma importante contextualização para a atividade hermenêutica.

Reconheço o risco de tal afirmação, mas prefiro reconsiderá-la depois, se for o caso, do que retirá-la da discussão.

Referindo-se à assertiva de Wayne Booth, segundo a qual "supracompreender consiste em fazer as perguntas que o texto parece não colocar a seu leitor-modelo"

Sobre a autora 